\title{
Cigarette smoking transition in females of low socioeconomic status: impact of state, school, and individual factors
}

\author{
Hyoshin Kim, Pamela I Clark
}

J Epidemiol Community Health 2006;60(Suppl II):ii13-ii19. doi: 10.1136/jech.2005.045658

See end of article for authors' affiliations

.....................

Correspondence to: Dr H Kim, Battelle Centers for Public Health Research and Evaluation, 1100 Dexter Avenue North, Suite 400 , Seattle, WA 98109, USA; kimh@ battelle.org

Accepted for publication 10 June 2006

\begin{abstract}
Study objective: To examine whether young, especially low socioeconomic status (SES), females are influenced by tobacco control policies in terms of smoking initiation and transition to more adverse stages of smoking behaviour from adolescence to young adulthood.

Design and setting: Data from 2697 young female respondents to the national longitudinal study of adolescent health wave 1 (1994-1995) and wave 3 (2001-2002).

Measurements: The following factors were used to predict the likelihood of smoking initiation and transition to heavier tobacco use between adolescence and young adulthood among females of low, middle, and high SES groups: state level tobacco control policy scores, developed by the US National Cancer Institute, state cigarette excise tax, smoking rate at school, cigarette availability at home, and number of best friends smoking.

Main results: Stronger state level tobacco policies were associated with lower likelihood of smoking initiation and adverse transition among low SES women, although the effect sizes were small. Adolescents who attended schools with higher student smoking rates; adolescents who had easier access to cigarettes at home; and adolescents who had more friends smoking were all more likely to be adverse transitioners by young adulthood.

Conclusions: State level tobacco control policies and individual level factors during adolescence are independently associated with smoking initiation and adverse transition by the onset of young adulthood, especially for low SES females. While states may have very little direct influence on individual level behaviours, through their policies they do have the potential to exert considerable influence on smoking behaviour that persists through adolescence into young adulthood.
\end{abstract}

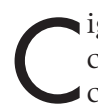
igarette smoking in the USA and other developed countries has been found to be associated with social class. ${ }^{12}$ Adult smoking is highly concentrated among those of lower socioeconomic status (SES), where SES is defined by educational attainment, income, and occupation. Consequently, those of low SES bear the heaviest health burden. To reduce such disparities, recent national initiatives like those of the Healthy People 2010 objectives have been undertaken, and various tobacco control policies have been enacted and implemented. ${ }^{3}$ Many of the policy initiatives are targeted at teenagers because most adult smokers start smoking before age $18 .^{4}$ Even in those younger than 18 , smoking initiation is known to be positively correlated with low household income. ${ }^{4-6}$ What is not well understood is how tobacco control policies affect smoking in young female adolescents, particularly those of low SES. The goal of this paper is an exploration of how tobacco control policies differentially influence female adolescents in low, middle, and high SES groups in terms of their smoking initiation and transition to a more detrimental or adverse (that is, heavier tobacco use) stage of smoking behaviour during the period from adolescence through young adulthood.

Early tobacco control research chiefly focused on the biobehavioural influences of smoking such as personality traits, family characteristics, and parental smoking status in an attempt to identify the characteristics of children and adolescents who were at risk of smoking. Consequent tobacco control interventions, such as school based educational programmes, were based upon this bio-behavioural demand-side model. More recently, tobacco control research has shifted to a focus on the environmental factors influencing tobacco use (for example, policies to reduce supply, raise tobacco taxes, and limit tobacco advertising and promotion). However, neither the bio-behavioural influences models nor the environmental influences models alone adequately explain why adolescents take up smoking or why they continue to smoke. Instead, models combining both of these two sources of influences-macro, distal environmental factors (for example, state and school related factors) and proximal factors (for example, individual, parent, family, and peer related factors) - offer an opportunity to examine how individual smoking behaviour is influenced by an interaction of multiple factors. Considering the interaction of these multiple factors is important because it is now recognised that although tobacco control policies do influence rates of adolescent smoking initiation and transition to heavier smoking, not all adolescents respond to policies in the same way. Indeed, a person's susceptibility or resilience towards smoking is mainly determined by demographic and proximal factors, which may be modified by the more distal policy environment, such as clean indoor air laws. ${ }^{7-9}$

In this paper we investigate the issue of whether state level tobacco control policies have an effect on smoking transitions from adolescence through young adulthood. Stated another way, do differences exist in the smoking behaviour of adolescents of low SES living in states with strong youth tobacco access policies compared with states with weak policies? Available evidence is sometimes contradictory. Most adolescents believe that cigarettes are readily available, ${ }^{10-13}$ and there is evidence to support that notion. In one study, $83 \%$ of those adolescents who ever smoked reported that they did not usually buy their own cigarettes, and adolescents 
whose best friends smoked were significantly more likely to report getting cigarettes from other smokers. ${ }^{14}$ Likewise, experimental smokers were more likely to rely on friends, peers, or family members for cigarettes. ${ }^{15}$ However, as they move to higher use rates adolescents must purchase cigarettes themselves, ${ }^{10}{ }^{11}$ thus smoking transition and commercial cigarette accessibility are linked.

Even though policies limiting youth access have been adopted at the local, state, and federal levels, debate over the effectiveness of youth access laws has not been silenced, partly because of a paucity of data on enforcement and partly because of methodological limitations of studies examining policy effectiveness. ${ }^{16-23}$ Regardless of the debate, policy enforcement seems to be an essential element in reducing sales to minors. ${ }^{24}{ }^{25}$ With the Synar Amendment (July 1992), federal block grants are conditional upon each state enacting and enforcing laws restricting the sale and distribution of tobacco products to minors. However, implementation of the laws has been slow: since 1996 each state has been required to conduct annual surveys of merchant compliance, but states failing to meet the requirements of the Synar Amendment have not been punished. This is the case even though several studies examining the impact of access laws concluded that enforcement and merchant compliance lead to reduced access to tobacco products and consequent reductions in adolescent smoking. ${ }^{1621-23}$ One experimental study in Illinois showed that active enforcement over a two year period resulted in not just a reduction of sales to minors, but a reduction in tobacco use by adolescents. ${ }^{22}$ These studies showing a positive relation between increased policy compliance and reductions in adolescent smoking are encouraging, but it should be understood that even if youth access law compliance by merchants were $100 \%$, adolescent smoking would not completely disappear. Adolescents will still procure cigarettes from other sources, such as friends or family. Indeed, any level of merchant compliance less than $100 \%$ guarantees that some adolescents will find a store willing to sell them cigarettes. ${ }^{26}$ Therefore, the effects of access laws are just one factor in adolescent smoking, albeit an important one.

The fundamental hypothesis of this study is that restricting commercial availability of tobacco to minors will make it more difficult for adolescents to obtain tobacco products, thereby delaying their smoking initiation. While the focus of the study is on the effects of state level tobacco control policies, we also consider multiple factors important in determining smoking transitions in the long run. Hence tobacco control related factors at school and individual levels during adolescence are examined together, along with state level tobacco control factors. In considering the long term influence of adolescent experiences, we hypothesise that the impact of tobacco control policies targeted at youths will extend into young adulthood, and that family and school experiences will have a sustained influence on smoking over the long term. In examining the effects of state tobacco control policies described above, we incorporate into our model measures of cigarette availability at home; number of best friends who smoked; and student smoking rates at school, while controlling for the effects of age; race and ethnicity; parent structure; and family bonding.

\section{METHODS}

Our dataset, the national longitudinal study of adolescent health (Add Health), is a school based survey of the health related behaviours of adolescents. Add Health ensures national representativeness by surveying individual adolescents from 132 schools, grades 7 to 12 , using a sampling frame stratified by region, level of urbanisation, school type, school size, and by school racial compositions. In 1994-5 (wave 1), data from 18924 adolescents were collected; in 1996 (wave 2) and in 2001-2 (wave 3), follow up in-home surveys were conducted to interview again 15197 of the respondents from wave 1 about their health behaviours and life experience as young adults. Data from wave 1 were used to operationalise outcome variables on smoking, demographic characteristics, family characteristics, parent's level of education, and family income (the latter two from the parent's questionnaire). A set of linked identifiers-data from the in-school survey, in-home wave 1 and wave 3 surveys, school administrator survey, and parent surveys, along with state tobacco control score data (described below)-were merged with detailed information about female respondents' behaviours related to smoking, as well as the characteristics of their families and friends, and their school and state. For analyses, the sample was restricted to adolescents younger than 18 years of age at wave 1 , namely those who could not legally purchase cigarettes, resulting in 2697 female cases from 33 states and 126 schools.

Female respondents were classified into five groups based on a hierarchy of increasing severity of smoking related behaviours..$^{28}$ Respondents who had: (1) never puffed a cigarette, classified as never smokers (the reference group in our multivariate analyses); (2) smoked an entire cigarette at least once but not every day in the past 30 days, classified as intermittent smokers; (3) smoked every day, classified as regular smokers; (4) smoked an entire cigarette at least once, but not in the past 30 days, and who claimed not to ever have been regular smokers, classified as experimental smokers; (5) formerly been a regular smoker and who had quit, classified as former smokers. To create subgroups for analyses, the classification of smoking stages was applied to female respondents who answered wave 1 Add Health in-home

Table 1 Definitions and sample sizes of adverse transitioners and initiators from classification of smoking stages

\begin{tabular}{|c|c|c|c|c|}
\hline \multicolumn{5}{|l|}{ Initiators } \\
\hline Smoker stage at wave 3 & Never smoked & Experimental & Intermittent & Regular \\
\hline \multicolumn{5}{|l|}{ Smoker stage at wave 1} \\
\hline Never smoked & 1,261 & 440 & 106 & 186 \\
\hline Experimental & - & - & - & - \\
\hline Intermittent & - & - & - & - \\
\hline \multicolumn{5}{|c|}{$\begin{array}{l}\text { *Never smoked }=63.3 \%(n=1261) \text {; initiators }=36.7 \%(n=732) \text {; total number }=1993 \\
\text { Adverse transitioners }\end{array}$} \\
\hline Smoker stage at wave 3 & Never smoked & Experimental & Intermittent & Regular \\
\hline \multicolumn{5}{|l|}{ Smoker stage at wave 1} \\
\hline Never smoked & 1,261 & 440 & 106 & 186 \\
\hline Experimental & - & - & 162 & 235 \\
\hline Intermittent & - & - & - & 307 \\
\hline \multicolumn{5}{|c|}{ *Never smoked $=46.8 \%(n=1261)$; adverse transitioners $=53.2 \%(n=1436)$; total number $=2697$} \\
\hline
\end{tabular}


Table 2 Description of predictors used in multivariate multilevel analyses

\begin{tabular}{|c|c|}
\hline Predictor at wave 1 & Description \\
\hline \multicolumn{2}{|l|}{ Individual level } \\
\hline Race/ethnicity & $\begin{array}{l}\text { White, Asian, Native American, or other race (reference group); Hispanic (yes, no); African } \\
\text { American (yes, no) }\end{array}$ \\
\hline Age & Age in years at wave 1 \\
\hline Parent structure & Lived with two biological parents (yes, no) \\
\hline Family bonding & $\begin{array}{l}\text { Mean of four questions on a five point Likert scale regarding respondent's feelings about } \\
\text { family bonding (for example, How much do you feel that your family pays attention to you?) }\end{array}$ \\
\hline Availability of cigarettes at home & Are cigarettes easily available to you in your home? (yes, no) \\
\hline Best friends' smoking & $\begin{array}{l}\text { Of your three best friends, how many smoke at least one cigarette a day? - None smoked } \\
\text { (reference group); one smoked (yes, no); two smoked (yes, no); three smoked (yes, no) }\end{array}$ \\
\hline \multicolumn{2}{|r|}{ 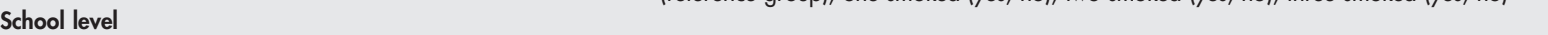 } \\
\hline Smoking student rates at school & $\begin{array}{l}\text { Percentage of students, who responded at least "once or twice" to Q: During the past } 12 \\
\text { months, how often did you smoke cigareftes? }\end{array}$ \\
\hline \multicolumn{2}{|l|}{ State level tobacco control policies } \\
\hline Statewide enforcement & Establishes a clearly designated statewide enforcement authority for sales. \\
\hline Random inspections & $\begin{array}{l}\text { Establishes random, unannounced inspections of retailers as part of the enforcement } \\
\text { mechanism, using underage buyers for the purpose of identifying violators, and does not } \\
\text { prohibit other use of minors to test compliance. }\end{array}$ \\
\hline Graduated penalties & $\begin{array}{l}\text { Establishes a system of graduated penalties or fines applicable to all youth access laws, to be } \\
\text { levied within three years, plus possibility of suspension or revocation of a required tobacco } \\
\text { retail licence for repeated sales to minors. }\end{array}$ \\
\hline Photo identification & $\begin{array}{l}\text { Requires merchants to request photographic identification for customers who appear to be } \\
\text { under } 21 \text { years of age. }\end{array}$ \\
\hline Free distribution & Total ban on distribution of free tobacco samples, coupons for free samples, or rebates. \\
\hline Minimum age & $\begin{array}{l}\text { Prohibits the sale or distribution of any tobacco products to persons less than } 18 \text { years of age } \\
\text { through any sales or distribution outlet, and a warning sign is required at point of purchase } \\
\text { with specific penally for failing to post a sign. }\end{array}$ \\
\hline Packaging & $\begin{array}{l}\text { Prohibits all cigarette sales other than in a sealed package conforming to federal labelling } \\
\text { requirements. }\end{array}$ \\
\hline Vending machines & Total ban on sale of all tobacco products through vending machines in all locations. \\
\hline Clerk intervention & Prohibits access to or purchase of tobacco products without the intervention of a sales clerk. \\
\hline State total score & Sum score of the nine items above* \\
\hline State cigarefte excise tax in 1995 & State cigarette excise tax in dollars \\
\hline
\end{tabular}

questionnaire in 1995 and who participated in the follow up wave 3 study in 2001-2. Data from the two time points, seven years apart*, permit inferences to be made about transitions in smoking behaviour. Different kinds of smoking transition might have occurred during the seven year time period, but the focus of this paper is on adverse transition (that is, a transition from one smoking classification stage in wave 1 to a more adverse stage in wave 3). An important subgroup of adverse transitioners is "initiators"- those who had never smoked in wave 1 but became a smoker in any stage in wave 3. In our analyses we compare: (1) initiators and never smokers; and (2) adverse transitioners and never smokers. Table 1 reports the definitions and sample sizes for smoking initiators and adverse transitioners.

For analyses, female respondents were classified into three groups, low SES, middle SES, and high SES based on both family income and parent education in wave 1. Missing values for family income were imputed. ${ }^{29}$ Based on the federal poverty level guidelines, four levels of family income were created: (1) below poverty level $(<100 \%$ of poverty level); (2) low income (100\%-199\%); (3) middle income $(200 \%-399 \%)$; and $(4)$ high income $(\geqslant 400 \%)$. Missing values for parent education were not imputed. Parent education level was combined with family income level to create SES groups; if the income level was below poverty level, then cases with missing values in parent education were classified as low SES. The three SES groups were constructed as follows: (1) low SES includes (a) cases from families below poverty level and all levels of parent education, and (b) cases from parent education less than high school graduate; (2) middle SES includes cases from (a) low income families/ parent education of high school or more, (b) middle income

"Because no cases in the former smoker category exist in wave 3, we will focus on the first four groups. families/parent education of high school or some college, and (c) high income families/parent education less than or high school graduate; (3) high SES includes cases from (a) high income level/parent education of some college or more, and (b) middle income/parent education of college graduate. Sample sizes were 1245 for low SES, 812 for middle SES, and 640 for high SES female adolescents.

For state level tobacco control policy variables, we adopted a measure of comprehensive state tobacco control efforts based on a score developed by the National Cancer Institute evaluating nine items for each state each year (see Alciati et al for further information about the rating system). ${ }^{30}{ }^{31}$ Three of the items cover law enforcement provisions (statewide enforcement, random inspections, graduated penalties); six cover specific tobacco control provisions (photo identification, free distribution, minimum age, packaging, vending machines, and clerk intervention). We also incorporated 1995 state excise tax data as a tobacco policy variable in separate models. For school level control measures (for example, penalties for smoking at school), we focused on the smoking rates of students in the schools attended by our respondents, selected from preliminary analyses. At the individual level, cigarette availability at home; extent of best friends' smoking; and family bonding were used. Control variables were age, race/ethnicity, and parent structure. Small sample sizes for Asian, Native American, and other race groups precluded analyses of these detailed categories of race/ ethnicity. Instead, three racial and ethnic groups, Hispanic, African American, and white and other racial groups (hereafter referred to as white group) were created.

To account for the nested structure of individual level data within states and schools, multilevel logistic regressions comparing initiators to never smokers were used. Low, middle, and high SES female adolescents were initially modelled separately to examine the possible overall effects of 
Table 3 Descriptive statistics of demographic/family characteristics; and tobacco control polices and tobacco control related factors at individual, school and state levels for low, middle, and high SES female groups by never smoked compared with adverse transition

\begin{tabular}{|c|c|c|c|c|c|c|c|c|c|c|c|c|}
\hline \multirow[b]{4}{*}{ Variable } & \multicolumn{4}{|c|}{ Low SES females } & \multicolumn{4}{|c|}{ Middle SES females } & \multicolumn{4}{|c|}{ High SES females } \\
\hline & \multirow{2}{*}{\multicolumn{2}{|c|}{$\begin{array}{l}\text { Never smoked } \\
(n=598)\end{array}$}} & \multirow{2}{*}{\multicolumn{2}{|c|}{$\begin{array}{l}\text { Adverse transition } \\
(n=647)\end{array}$}} & \multirow{2}{*}{\multicolumn{2}{|c|}{$\begin{array}{l}\text { Never smoked } \\
(n=350)\end{array}$}} & \multirow{2}{*}{\multicolumn{2}{|c|}{$\begin{array}{l}\text { Adverse transition } \\
(n=462)\end{array}$}} & \multirow{2}{*}{\multicolumn{2}{|c|}{$\begin{array}{l}\text { Never smoked } \\
(n=313)\end{array}$}} & \multirow{2}{*}{\multicolumn{2}{|c|}{$\begin{array}{l}\text { Adverse transition } \\
(n=327)\end{array}$}} \\
\hline & & & & & & & & & & & & \\
\hline & Mean & SD & Mean & SD & Mean & SD & Mean & SD & Mean & SD & Mean & SD \\
\hline \multicolumn{13}{|l|}{ Individual level characteristics } \\
\hline \multicolumn{13}{|l|}{ Race/ethnicity } \\
\hline White and other races $(1,0)$ & $37.6 \%$ & & $55.3 \%$ & & $53.1 \%$ & & $70.6 \%$ & & $63.6 \%$ & & $82.3 \%$ & \\
\hline Hispanic $(1,0)$ & $22.4 \%$ & & $17.2 \%$ & & $12.9 \%$ & & $8.9 \%$ & & $3.2 \%$ & & $3.7 \%$ & \\
\hline African American $(1,0)$ & $40.0 \%$ & & $27.5 \%$ & & $34.0 \%$ & & $20.6 \%$ & & $33.2 \%$ & & $14.1 \%$ & \\
\hline Age at wave 1 & 15.22 & 1.44 & 14.89 & 1.49 & 14.79 & 1.56 & 14.64 & 1.51 & 14.68 & 1.61 & 14.71 & 1.45 \\
\hline \multicolumn{13}{|c|}{ Family income level (federal poverty level) } \\
\hline Poor $(<100 \%)$ & $84.8 \%$ & & $84.2 \%$ & & - & & - & & - & & - & \\
\hline Low income (100\%-199\%) & $9.9 \%$ & & $9.1 \%$ & & $52.9 \%$ & & $51.5 \%$ & & - & & - & \\
\hline Middle income (200\%-399\%) & $5.4 \%$ & & $6.6 \%$ & & $38.9 \%$ & & $38.5 \%$ & & $40.6 \%$ & & $37.3 \%$ & \\
\hline High income $(\leqslant 400 \%)$ & - & & - & & $8.3 \%$ & & $10.0 \%$ & & $59.4 \%$ & & $62.7 \%$ & \\
\hline \multicolumn{13}{|l|}{ Parent's education ${ }^{*}$} \\
\hline Less than high school $(1,0)$ & $47.4 \%$ & & $48.3 \%$ & & $1.7 \%$ & & $1.9 \%$ & & - & & - & \\
\hline High school graduate $(1,0)$ & $16.1 \%$ & & $21.1 \%$ & & $26.6 \%$ & & $27.5 \%$ & & - & & - & \\
\hline Some college $(1,0)$ & $22.1 \%$ & & $21.6 \%$ & & $60.6 \%$ & & $64.1 \%$ & & $16.0 \%$ & & $24.5 \%$ & \\
\hline College or higher $(1,0)$ & $14.5 \%$ & & $9.1 \%$ & & $11.1 \%$ & & $6.5 \%$ & & $84.0 \%$ & & $75.5 \%$ & \\
\hline \multicolumn{13}{|l|}{ Parent structure } \\
\hline $\begin{array}{l}\text { Lived with two biological parents } \\
(1,0)\end{array}$ & $48.5 \%$ & & $44.4 \%$ & & $56.3 \%$ & & $47.8 \%$ & & $72.5 \%$ & & $67.9 \%$ & \\
\hline Family bonding $(1-5)$ & 4.15 & 0.67 & 3.94 & 0.78 & 4.18 & 0.65 & 3.94 & 0.68 & 4.20 & 0.64 & 4.08 & 0.63 \\
\hline $\begin{array}{l}\text { Cigarette easily available at home } \\
(1,0)\end{array}$ & $20.9 \%$ & & $37.1 \%$ & & $23.4 \%$ & & $36.6 \%$ & & $11.8 \%$ & & $22.9 \%$ & \\
\hline \multicolumn{13}{|l|}{ Among three best friends... } \\
\hline None smoked $(1,0)$ & $76.4 \%$ & & $56.6 \%$ & & $83.7 \%$ & & $55.4 \%$ & & $86.6 \%$ & & $68.5 \%$ & \\
\hline One smoked $(1,0)$ & $15.1 \%$ & & $21.6 \%$ & & $12.3 \%$ & & $21.6 \%$ & & $9.9 \%$ & & $16.2 \%$ & \\
\hline Two smoked $(1,0)$ & $5.0 \%$ & & $12.5 \%$ & & $2.0 \%$ & & $13.0 \%$ & & $2.6 \%$ & & $11.3 \%$ & \\
\hline Three smoked $(1,0)$ & $3.5 \%$ & & $9.3 \%$ & & $2.0 \%$ & & $10.0 \%$ & & $1.0 \%$ & & $4.0 \%$ & \\
\hline School level characteristics & $(n=110)$ & & $(n=118)$ & & $(n=107)$ & & $(n=118)$ & & $(n=93)$ & & $(n=94)$ & \\
\hline Smoking rates at school (\%) & 33.28 & 11.18 & 33.92 & 10.44 & 33.05 & 10.96 & 33.31 & 10.62 & 31.82 & 10.99 & 33.96 & 10.60 \\
\hline State level tobacco control policies & $(n=32)$ & & $(n=32)$ & & $(n=32)$ & & $(n=32)$ & & $(n=32)$ & & $(n=31)$ & \\
\hline State total score $†$ & 8.38 & 4.92 & 8.63 & 5.05 & 8.28 & 4.75 & 8.28 & 4.75 & 8.38 & 4.92 & 8.55 & 4.90 \\
\hline Statewide enforcement & 1.50 & 1.90 & 1.50 & 1.90 & 1.50 & 1.90 & 1.50 & 1.90 & 1.50 & 1.90 & 1.55 & 1.91 \\
\hline Random inspections & 1.13 & 1.60 & 1.00 & 1.52 & 1.13 & 1.60 & 1.13 & 1.60 & 1.13 & 1.60 & 1.16 & 1.61 \\
\hline Graduated penalties & 1.47 & 1.52 & 1.59 & 1.56 & 1.47 & 1.52 & 1.47 & 1.52 & 1.47 & 1.52 & 1.52 & 1.52 \\
\hline Photo identification & 0.53 & 1.16 & 0.59 & 1.19 & 0.53 & 1.16 & 0.53 & 1.16 & 0.53 & 1.16 & 0.55 & 1.18 \\
\hline Free distribution & 0.34 & 0.70 & 0.34 & 0.70 & 0.34 & 0.70 & 0.34 & 0.70 & 0.34 & 0.70 & 0.35 & 0.71 \\
\hline Minimum age & 3.63 & 0.49 & 3.66 & 0.48 & 3.63 & 0.49 & 3.63 & 0.49 & 3.63 & 0.49 & 3.65 & 0.49 \\
\hline Packaging & 1.00 & 1.65 & 0.88 & 1.56 & 0.91 & 1.61 & 0.91 & 1.61 & 1.00 & 1.65 & 1.03 & 1.66 \\
\hline Vending machines & 0.69 & 0.69 & 0.72 & 0.68 & 0.69 & 0.69 & 0.69 & 0.69 & 0.69 & 0.69 & 0.71 & 0.69 \\
\hline Clerk intervention & 0.00 & - & 0.00 & - & 0.00 & - & 0.00 & - & 0.00 & - & 0.00 & - \\
\hline State tax 1995 in \$ & 0.30 & 0.17 & 0.30 & 0.17 & 0.29 & 0.17 & 0.29 & 0.17 & 0.30 & 0.17 & 0.30 & 0.17 \\
\hline
\end{tabular}

tobacco control policies in general. Later, a series of models incorporating individual policy items, one at a time, was developed to evaluate the effect of each individual policy. School level characteristics and individual level characteristics were included in the models, along with basic demographic characteristics as controls. The analyses were repeated for adverse transitioners compared with never smokers to assess policy effects on the three SES groups.

\section{RESULTS}

Table 3 reports the descriptive statistics of predictors at the individual level by low, middle, and high SES females for never smoked and initiation groups, as well as for never smoked and adverse transition groups.

Table 4 reports the odds ratios of smoking initiation and adverse transition for low, middle and high SES female groups. Our hypothesis that state level tobacco control policies reduce the likelihood of smoking initiation and adverse transition was supported. Stronger state tobacco control policies are in general positively associated with a lower likelihood of initiation and adverse transition. The positive policy effects for initiation were strongest for low
SES females, whose odds ratio was 0.95 ( 0.98 for middle SES, 1.00 for high SES). For initiation, school level smoking rates did not vary substantially across low, middle, and high SES groups $(\mathrm{OR}=1.01,0.99$ and 1.00 , respectively), a finding consistent with the research of others. ${ }^{32}$

The pattern of results for adverse transition was overall very similar to that of initiation, and consistent with prior research by others. Individual level tobacco control variables, such as cigarette availability at home and best friends' smoking, were significantly associated with the likelihood of adverse transition (typically estimates did not reach statistical significance for initiation). Availability of cigarettes at home was associated with greater odds of initiation and adverse transition in all SES groups. If there were best friends who smoked, the odds of initiation and adverse transition increased (significantly so for transition, less significantly for initiation). Of note, there was a consistent pattern of having one, two, or three best friends smoking associated with initiation and adverse transition, but it was not the linear relation seen for other variables, such as state policy effects, wherein greater effects for the low SES group were seen. Instead we see that the more pronounced effects are on the 
Table 4 Estimated odds ratios (OR) from multilevel logistic regressions for the effects of state tobacco control policies, and school and individual level tobacco control factors on smoking initiation and adverse transition in low, middle, and high SES female groups

\begin{tabular}{|c|c|c|c|c|c|c|c|c|c|c|c|c|}
\hline \multirow[b]{3}{*}{ Variable } & \multicolumn{6}{|c|}{ Initiation compared with never smoked } & \multicolumn{6}{|c|}{ Adverse transition compared with never smoked } \\
\hline & \multicolumn{2}{|c|}{ Low SES } & \multicolumn{2}{|c|}{ Middle SES } & \multicolumn{2}{|c|}{ High SES } & \multicolumn{2}{|c|}{ Low SES } & \multicolumn{2}{|c|}{ Middle SES } & \multicolumn{2}{|c|}{ High SES } \\
\hline & OR & p Value & OR & p Value & OR & $\mathrm{p}$ Value & OR & p Value & OR & p Value & OR & $\mathrm{p}$ Value \\
\hline \multicolumn{13}{|l|}{ State level } \\
\hline State total score & 0.95 & 0.008 & 0.98 & 0.36 & 1.00 & 0.88 & 0.96 & 0.009 & 0.98 & 0.25 & 1.01 & 0.38 \\
\hline \multicolumn{13}{|l|}{ School level } \\
\hline Smoking rates at school (\%) & 1.01 & 0.19 & 0.99 & 0.50 & 1.00 & 0.92 & 1.02 & 0.006 & 1.01 & 0.10 & 1.01 & 0.57 \\
\hline \multicolumn{13}{|l|}{ Individual level } \\
\hline \multicolumn{13}{|l|}{ Cigarettes availability at home } \\
\hline Not easily available at home & 1.00 & - & 1.00 & - & 1.00 & - & 1.00 & - & 1.00 & - & 1.00 & - \\
\hline Easily available at home & 1.48 & 0.02 & 1.57 & 0.03 & 2.00 & 0.01 & 1.65 & $<0.001$ & 1.46 & 0.03 & 2.50 & $<0.001$ \\
\hline \multicolumn{13}{|l|}{ Among three best friends... } \\
\hline No best friend smoked & 1.00 & - & 1.00 & - & 1.00 & - & 1.00 & - & 1.00 & - & 1.00 & - \\
\hline One best friend smoked & 1.07 & 0.75 & 1.68 & 0.05 & 1.11 & 0.74 & 1.59 & 0.001 & 2.39 & $<0.0001$ & 1.79 & 0.03 \\
\hline Two best friend smoked & 1.42 & 0.24 & 2.92 & 0.04 & 2.21 & 0.13 & 2.59 & $<0.0001$ & 7.61 & $<0.0001$ & 4.75 & $<0.001$ \\
\hline Three best friend smoked & 1.11 & 0.79 & 1.40 & 0.57 & 1.16 & 0.88 & 2.67 & 0.001 & 4.94 & $<0.001$ & 4.33 & 0.03 \\
\hline \multicolumn{13}{|c|}{ When state tobacco control policy variables used as a single variable in separate models } \\
\hline Statewide enforcement & 0.89 & 0.03 & $0.91^{\circ}$ & 0.06 & 1.00 & 0.96 & 0.91 & 0.02 & 0.91 & 0.03 & 1.02 & 0.61 \\
\hline Random inspections & 0.88 & 0.07 & 0.90 & 0.07 & 0.94 & 0.35 & 0.90 & 0.06 & 0.90 & 0.04 & 0.99 & 0.90 \\
\hline Graduated penalties & 0.99 & 0.89 & 0.99 & 0.91 & 1.05 & 0.50 & 0.99 & 0.83 & 0.99 & 0.92 & 1.02 & 0.67 \\
\hline Photo identification & 0.85 & 0.05 & 0.95 & 0.53 & 1.10 & 0.36 & 0.89 & 0.07 & 0.98 & 0.77 & 1.11 & 0.25 \\
\hline Free distribution & 0.81 & 0.13 & 0.95 & 0.61 & 0.99 & 0.91 & 0.83 & 0.07 & 0.99 & 0.88 & 1.02 & 0.85 \\
\hline Minimum age & 0.89 & 0.64 & 0.93 & 0.75 & 1.29 & 0.29 & 0.94 & 0.74 & 0.83 & 0.31 & 1.33 & 0.16 \\
\hline Packaging & 0.97 & 0.70 & 0.95 & 0.36 & 1.08 & 0.20 & 0.96 & 0.47 & 0.95 & 0.23 & 1.08 & 0.15 \\
\hline Vending machine & 0.92 & 0.54 & 0.84 & 0.17 & 0.96 & 0.74 & 0.92 & 0.48 & 0.93 & 0.49 & 1.05 & 0.66 \\
\hline State cigarette excise tax 1995 & 1.53 & 0.52 & 0.97 & 0.96 & 2.28 & 0.23 & 0.84 & 0.74 & 1.51 & 0.42 & 2.37 & 0.15 \\
\hline \multicolumn{13}{|c|}{ Other individual level demographic/family characteristics } \\
\hline \multicolumn{13}{|c|}{ Race/ethnicity } \\
\hline White and other races & 1.00 & - & 1.00 & - & 1.00 & - & 1.00 & - & 1.00 & - & 1.00 & - \\
\hline Hispanic & 1.30 & 0.24 & 0.70 & 0.27 & 0.54 & 0.31 & 1.03 & 0.88 & 0.73 & 0.24 & 0.63 & 0.34 \\
\hline African American & 0.80 & 0.24 & 0.78 & 0.26 & 0.33 & $<0.0001$ & 0.57 & $<0.001$ & 0.58 & 0.001 & 0.28 & $<0.0001$ \\
\hline Age & 0.79 & $<0.0001$ & 0.87 & 0.03 & 0.94 & 0.45 & 0.80 & $<0.001$ & 0.85 & 0.001 & 0.97 & 0.61 \\
\hline \multicolumn{13}{|l|}{ Parent structure } \\
\hline Not lived with two biological parents & 1.00 & - & 1.00 & - & 1.00 & - & 1.00 & - & 1.00 & - & 1.00 & - \\
\hline Lived with two biological parents & 0.84 & 0.25 & 0.89 & 0.56 & 0.93 & 0.72 & 0.82 & 0.14 & 0.75 & 0.08 & 0.75 & 0.14 \\
\hline Family bonding & 0.90 & 0.33 & 0.74 & 0.04 & 1.01 & 0.95 & 0.74 & $<0.001$ & 0.66 & 0.001 & 0.79 & 0.09 \\
\hline \multirow[t]{2}{*}{ Sample size } & \multicolumn{4}{|c|}{$\begin{array}{r}126 \text { schools; } 33 \text { states; } 123 \text { schools; } 32 \\
\text { states; }\end{array}$} & \multicolumn{4}{|c|}{109 schools; 32 states; 126 schools; 33 states } & \multicolumn{4}{|c|}{123 schools; 32 states; 109 schools; 32 states; } \\
\hline & \multicolumn{2}{|c|}{932 females } & \multicolumn{2}{|c|}{551 females } & $510 \mathrm{fe}$ & ales & 1245 & ales & $812 \mathrm{fe}$ & nales & $640 \mathrm{fe}$ & \\
\hline
\end{tabular}

middle SES group (for example, with two best friends smoking, the transition odds ratios for low, middle, and high SES female groups are, respectively, 2.95, 7.61, and 4.75). However, for low SES females, having more best friends smoking translates into a higher likelihood of adverse transition (OR increasing from 1.59 to 2.67).

We also evaluated the effects of eight of the individual policies $†$ in separate models for enforcement related policies: (1) statewide enforcement, (2) random inspections, and (3) graduated penalties, and access related policies, (4) photo identification, (5) free distribution, (6) minimum age, (7) packaging, and (8) vending machines. With respect to smoking initiation, we found that two of the three enforcement related policy variables (statewide enforcement and random inspections) and one of the five access related policy variables (photo identification) represent the most significant effects of the policies. But almost every control policy had the same pattern: higher levels of controls lead to lower likelihoods of initiation for lower SES females. In other words, tobacco control policies have the biggest impact on reducing the likelihood of smoking initiation in low SES females, less of an impact on the likelihood of middle SES female group, and the least impact on high SES females. Indeed, for initiation there were almost no positive effects

${ }^{\dagger}$ Clerk intervention item was not included for analyses because no states received any positive score for this item in 1995. noted for any control policy on those female adolescents in the high SES group, a pattern that was even more pronounced for the adverse transition analyses results. This point will be discussed in a later section of the paper. To illustrate the positive effects of specific control policies, we focus on three of them. Firstly, for statewide enforcement, the odds ratios of initiation were significantly lower for the low (0.89) and middle (0.91) SES female groups; on the other hand, the policy had no effect on the high SES female group $(\mathrm{OR}=1.00)$. Secondly, for random inspections the odds ratios of initiation were significantly lower for low (0.88) and middle (0.90) SES female groups. Finally, photo identification had a significant positive effect on the low SES female group $(\mathrm{OR}=0.85)$, but not on the middle SES female group (OR $=0.95$, NS) and on high SES females $(\mathrm{OR}=1.10$, NS $)$. However, other policies had a pattern similar to the significant ones (that is, tobacco control policies have the biggest impact as SES decreases), one example of which is free distribution, where the odds ratios were $0.81,0.95$ and 0.99 respectively for low, middle, and high SES.

The results for the analyses of adverse smoking transition (as defined in the Method section) were virtually identical in pattern. They can be summarised as follows: stronger tobacco control policies are positively related to lower likelihood of adverse transition in smoking, especially for the low SES female group. Although most of the estimates did not reach 
conventional levels of statistical significance, the magnitude and the direction of the policy effects were none the less encouraging, especially for the low SES female group.‡

In summary, stronger state tobacco control policies are associated with lower likelihood of smoking initiation and adverse transition. These policies had a larger impact on low SES than on middle and high SES female groups. Individual level tobacco control factors, such as the availability of cigarettes at home and best friends' smoking, were powerful predictors of adverse transition as well. Given the minimal level of tobacco control policies across states at the time data were collected (before the Synar Amendment was fully implemented), the results clearly show an encouraging association between stronger policies and lower likelihood. Therefore, if states increase their effort levels, we can reasonably expect to see positive effects in reducing adverse transition.

\section{DISCUSSION}

Because stronger state tobacco control policies are especially associated with lower likelihood of smoking initiation and adverse transition in low and middle SES female groups, policies related to enforcement provisions have the potential to decrease adverse transition-if properly implemented. Results for the low SES female group are especially noteworthy: stronger policies are associated with lower likelihood of adverse transition for both low and middle SES female groups, but not necessarily for the high SES female group. Somewhat surprisingly, there were no positive effects for high SES females. Indeed, they sometimes had the opposite sign, although none of estimates were statistically significant. A possible explanation for the lack of policy effect may be that high SES females have access to other sources of cigarettes. The small effect sizes generally seen even for low SES females should be viewed in light of the fact that levels of state tobacco control efforts reported in the data are far from target levels. Further studies that track the effectiveness of state level policies should be undertaken regularly as tobacco control efforts ramp up toward their target levels.

It is also important to bear in mind that the tobacco control polices included in this analysis measure just the existence of a policy, not its implementation or the actual enforcement of laws. Two states might have identical laws, but enforce them quite differently. Or laws may be implemented selectively. As an example, consider that previous studies show girls have an easier time purchasing tobacco products from stores than boys; in fact, clerks more frequently encourage girls to buy cigarettes, and request identification less frequently from them than boys. ${ }^{33-35}$ Race and ethnicity of clerks also influence tobacco sales to minors-African American clerks are less likely to sell to minors. ${ }^{35}$ What this suggests is that

\section{What this paper adds}

Past studies of the effects of tobacco control polices and factors on general population have been conducted, but few studies have investigated the impact of tobacco control policies and factors on the subpopulation of the low socioeconomic status female group. In this study, although the effect sizes are small, stronger state level tobacco control policies are associated with lower likelihood of smoking initiation and adverse transition, especially for low SES females.

${ }^{\ddagger}$ No significant interaction effects between race/ethnicity indicators and state tobacco control policies were obtained. Therefore, only the main effects were reported and discussed in the paper. the proper implementation and rigourous enforcement of photo identification and clerk intervention policies, both involving an active interaction between merchants and buyers, could be quite effective in deterring access to tobacco products, especially for initiators. Indeed, photo identification was strongly associated with lower likelihood of initiation and adverse transition among low SES females. The reason that photo identification was not associated with middle and high SES female groups is unclear. It might be because middle and high SES female groups are more likely to obtain cigarettes from social sources instead of stores, or might it be because stores in middle or high SES females' neighbourhoods do not check photo identification to the same extent as stores in low SES neighbourhoods. If laws are enforced selectively and if low SES is correlated with geographical locality, then the differential effects we see for state policies may be attributable less to the actual state policy and more to its enforcement. The question of clerk intervention effectiveness is yet to be determined, as no state received a positive score in 1995. It may be that clerk intervention could be an effective policy, but difficult to implement. Future research regarding this should determine the answer.

A further consideration of study limitations is that of the seven year gap of the Add Health data used for the analyses of predicting the association of tobacco control polices between adolescence and young adulthood-a long time span for adolescents experiencing numerous transformative events in their life (becoming independent, moving away from home, starting college, starting jobs, and so on). Many factors, some possibly important, in determining smoking behaviour are therefore missing from the two waves of the Add Health data. A related issue is the timing of the collection of the data we used. In 1992, when enactments of the Synar Amendment were gradually being implemented, the average compliance rate for 93 US cities was 23\%. ${ }^{36}$ By 2001 the average of all state compliance rates was $83 \%$ and nine states reported compliance rates above $90 \%{ }^{21}$ In our analyses, we were limited to available data, but data collected in the future may show a different pattern. We also intentionally focused our attention on low SES and other SES female groups, and so did not examine similarities or differences of gender in the data. As the data already exist, it would be worthwhile analysing smoking and SES for men to see if additional insights on the effectiveness of policy might not be gleaned. Finally, the data were not experimental, so caution is needed when interpreting the findings, especially for causality.

What is not in question is that factors at the individual level are all important predictors for adverse transition. Girls who have easy access to cigarettes at home, and girls who have more friends smoking, are all more likely to be adverse transitioners. An especially strong association was noted between the number of best friends smoking during the teen

\section{Policy implications}

While individual level factors (such as friends and family) have a profound impact on smoking, state level policies, such as tobacco access laws, have a substantial positive impact on smoking for the low SES female group. Although states may have very little direct influence on individual level behaviours, through their policies they do have the potential to exert considerable influence on smoking behaviour, which persists through adolescence into young adulthood. For the low SES female group in particular, the greatest promise of deterring them from smoking in later life may well lie in the policies implemented during their adolescence. 
years for all SES women and their adverse transition to smoking, possibly because having more smoking friends means more sources of tobacco. School level predictors, in general, were not important predictors. Student smoking rates at school were only marginally associated with the odds of adverse transition in smoking, which is consistent with the findings of most previous research that school interventions are not effective in lowering smoking rates in the long run. ${ }^{32}$

In conclusion, state level tobacco control policies and individual level factors during adolescence are independently associated with smoking initiation and adverse transition by the onset of young adulthood, especially for the low female SES group. While states may have very little direct influence on individual level behaviours, through their policies they do have the potential to exert considerable influence on smoking behaviour that persists through adolescence into young adulthood. For the low SES female group in particular, the greatest promise of deterring them from smoking in later life may well lie in policies implemented during their adolescence.

\section{ACKNOWLEDGEMENTS}

We thank the anonymous reviewer for the helpful comments and suggestions, and Anne Rodgers for her editorial suggestions on an earlier version of this paper. We are grateful for the comments and suggestions provided by participants in the "Tobaccol Control Policies: Do they make a difference for low SES women and girls?" meeting, sponsored by the National Cancer Institute, the Department of Health and Human Services, and the American Legacy Foundation.

\section{Authors' affiliations}

H Kim, P I Clark, Battelle Centers for Public Health Research and Evaluation, Seattle and Baltimore, USA

Funding: this research was supported by grant RO3 CA105989-01 from the National Cancer Institute. Its contents are solely the responsibility of the authors and do not necessarily represent the official view of the National Cancer Institute.

Conflicts of interest: none.

\section{REFERENCES}

1 Barbeau EM, Leavy-Sperounis A, Balbach, eds. Smoking, social class, and gender: what can public health learn from the tobacco industry about disparities in smoking? Tob Control 2004;13:115-20.

2 Centers for Disease Control and Prevention. Cigarette smoking among adults - United States 2002. MMWR Morb Mortal Wkly Rep 2004;53:427-31

3 US Department of Health and Human Services. Healthy people 2010: with understanding and improving health and objectives for improving health. Washington, DC: US Department of Health and Human Services, 2000.

4 US Department of Health and Human Services. Preventing tobacco use among young people, A report of the surgeon general, 1994. Atlanta, GA: Public Health Service, Centers for Disease Control and Prevention, Office on Smoking and Health, 1994.

5 Voorhees CC, Schreiber GB, Schumann BC, et al. Early predictors of daily smoking in young women: the national heart, lung, and blood institute growth and health study. Prev Med 2002;34:616-24.

6 Graham H, Der G. Influences on women's smoking status. Eur J Public Health 1999;9:137-41.
7 Tauras JA, Chaloupka FJ. Price, clean indoor air laws and cigarette smoking: evidence from longitudinal data from young adults. Cambridge: National Bureau of Economic Research, 1999.

8 Wakefield M. Chaloupka F. Effectiveness of comprehensive tobacco control programmes in reducing teenage smoking in the USA. Tob Control 2000;9:177-86.

9 Wakefield M, Forster J. Growing evidence for new benefit of clean indoor air laws: reduced adolescent smoking. Tob Control 2005; 14:292-3.

10 US Centers for Disease Control. Accessibility of cigarettes to youths aged 1217 years-United States, 1989. MMWR Morb Mortal Wkly Rep 1992;41:485-8.

11 Cummings KM, Sciandra E, Pechacek TF, et al. Where teenagers get their cigarettes: a survey of the purchasing habits of 13-16 year olds in 12 US communities. Tob Control 1992;1:264-7.

12 Forster JL, Hourigan M, McGovern P. Availability of cigarettes to underage youth in three communities. Prev Med 1992;21:320-8

13 Jones SE, Sharp DJ, Husten CG, et al. Cigarette acquisition and proof of age among US high school students who smoke. Tob Control 2002;11:20-5.

14 Pierce JP, Gilpin EA, Emery SL, et al. Tobacco control in California: Who's winning the war? An evaluation of the Tobacco Control Program, 19891996. La Jolla, CA: University of California, San Diego, 1998.

15 Pierce JP, Gilpin EA, Emery SL, et al. Has the California tobacco control program reduced smoking? JAMA 1998;280:893-9.

16 Jacobson PD, Lantz PM, Warner KE, et al. Combating teen smoking: research and policy strategies. Michigan: University of Michigan Press, 2001.

17 Stead LF, Lancaster T. A systematic review of interventions for preventing tobacco sales to minors. Tob Control 2000;9:169-76.

18 Ling PM, Landman A, Glantz SA. It is time to abandon youth access tobacco programmes. Tob Control 2002;11:3-6.

19 Fichtenberg CM, Glantz SA. Youth access interventions do not affect youth smoking. Pediatrics 2002;109:1088-92.

20 Difranza JR, Fichtenberg CM, Glantz SA, et al. Is it time to abandon youth access programmes? Authors' replies. Tob Control 2002;11:282-4.

21 Difranza JR. Restricted access to tobacco reduces smoking rates among youth. In: Owing JH, eds. Focus on smoking and health research. Hauppauge, NY: Nova Science, 2005:77-100.

22 Jason LA, Ji PY, Anes MD, et al. Active enforcement of cigarette control laws in the prevention of cigarette sales to minors. JAMA 1991;266:3159-61.

23 Forster JL, Murray DM, Wolfson M, et al. The effects of community policies to reduce youth access to tobacco. Am J Public Health 1998;88:1193-8.

24 Rigotti NA, DiFranza JR, Chang Y, et al. The effect of enforcing tobacco-sales laws on adolescents' access to tobacco and smoking behavior. N Engl J Med 1998;338:472-3.

25 Difranza JR, Rigotti NA. Impediments to the enforcement of youth access laws. Tob Control 1999;8:152-5.

26 Levy D, Friend K. Strategies for reducing youth access to tobacco: a review of the literature and framework for future research. Drugs, Education, Prevention and Policy 2002;9:285-303.

27 Lloyd-Richardson EE, Papandonatos G, Kazura, A, et al. Differentiating stages of smoking intensity among adolescents: stage-specific psychological and social influences. J Consult Clin Psychol 2002;70:998-1009.

28 Flay BR. Nicotine addiction: principles and management. New York: Oxford University Press, 1993.

29 Little RJA. Rubin DB. Statistical analysis with missing data. New York: Wiley, 1987.

30 Alciati MH, Frosh M, Green SB, et al. State laws on youth access to tobacco in the United States: measuring their extensiveness with a new rating system. Tob Control 1998;7:345-52.

31 Chriqui JF, Frosh MM, Fues LA, et al. State laws on youth access to tobacco: an update, 1993-1999. Tob Control 2002;11:163-4.

32 Backinger $\mathrm{CL}$, Fagan $\mathrm{P}$, Matthews $\mathrm{P}$, et al. Adolescent and young adult tobacco prevention and cessation: current status and future directions. Tob Control 2003; 12:46-53.

33 Forster JL, Hourigan M, McGovern P. Availability of cigarettes to underage youth in three communities. Prev Med 1992;21:320-8.

34 Wakefield M, Carrangis J, Wilson D, et al. Illegal cigarette sales to children in South Australia. Tob Control 1992;1:114-17.

35 Erickson AD, Woodruff SI, Wildey MB, et al. A baseline assessment of cigarette sales to minors in San Diego County, California. J Community Health 1993;18:213-24.

36 Radecki TE, Zdunich CD. Tobacco sales to minors in 97 US and Canadian communities. Tob Control 1993;2:300-5. 